\title{
STANDARD OF ORGANIZATION FOR GARLIC POWDER ENRICHED WITH SELENIUM
}

\author{
Шило Л.М. - кандидат с.-х. наук \\ с.н.с. лаб. стандартизации, нормирования и метрологии \\ Павлов Л.В.* - доктор с.-х. наук \\ зав. лаб. стандартизации, нормирования и метрологии \\ Голубкина Н.А.** - доктор с.-х. наук \\ главный н.с. лабораторно-аналитического центра \\ Середин Т.М. - кандидат с.-х. наук, с.н.с. лаб. селекции \\ и семеноводства луковых культур \\ Баранова Е.В. - кандидат с.-х. наук, н. с. лаб. селекции \\ и семеноводства луковых культур \\ Кошеваров А.А. - н.с. лабораторно-аналитического центра \\ Федеральное бюджетное научное учреждение \\ «Федеральный научный центр овощеводства» \\ 143072, Россия, Московская обл., \\ Одинцовский р-н, п. ВНИИССОК, ул. Селекционная, д. 14 \\ *E-mail: Pavlov.l.v@vniissok.ru \\ ** E-mail: segolubkina45@gmail.com
}

Установлены требования к порошку чеснока, обогащенному селе-

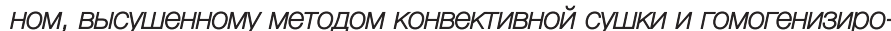
ванному. Обогащенные селеном овощи обладают особыми лечебными свойствами и представляют интерес как источник селена. Чеснок, обогащенный селеном, выращивают в ряде стран (в том числе в США, фирма Sabinsa) и выпускают в виде капсул, таблеток и гранул (БАД), как препаратов, способных защитить от возникновения и развития кардиологических и ряда онкологических заболеваний. Изучены и определены технические условия чесно ка сушеного с повышенным содержанием селена. На основе этих показателей разработан стандарт организации "Чеснок сушеный с повышенным содержанием селена. Технические условия». Стандарт разработан впервые для РФ. Селенат вносили в почву в дозе 75 мг/м² селената натрия. Для сушки использовали головки чеснока в биологической спелости, стандартные и нестандартные, без повреждения болезнями и вредителями. Зубки очищали от шелухи, измельчали и высушивали в сушильном шкафу при температуре $70^{\circ} \mathrm{C}$ до постоянной массы. Полученный материал гомогенизировали, порошок хранили в герметично закрытых полиэтиленовьх пакетах.

Ключевые слова: стандарт организации, чеснок сушеный с повышенным содержанием селена, технические условия.

Для цитирования: Шило Л.М., Павлов Л.В., Голубкина Н.А., Середин Т.М., Баранова Е.В., Кошеваров А.А. СТАНДАРТ ОРГАНИЗАЦИИ НА ПОРОШОК ЧЕСНОКА, ОБОГАЩЕННОГО СЕЛЕНОМ. ОВОЩИ РОССИИ. 2019;(1):60-64. DOl:10.18619/2072-9146-2019-1-60-64

богащенные селеном овощи обладают особыми лечебными свойствами и представляют интерес как источник селена. Чеснок, обогащенный селеном, выращивают в ряде стран (в том числе в США, фирма Sabinsa) и выпускают в виде капсул, таблеток и гранул (БАД), как препаратов, способных защитить от возникновения и развития кардиологических и ряда онкологических заболеваний.

Чеснок (Allium sativum L.) - однолетнее луковичное растение - является мощным кардиопротектором, иммуномодулятором, обладает противораковым, противовоспалительным, антибактериальным, противовирусным действием (Mikaili et al,
Shilo L.M. - PhD in Agriculture,

Senior Researcher

Pavlov L.V.* - doctor in Agriculture Sciences,

Head. of lab. standardization, regulation and metrology

Golubkina N.A.** - doctor in Agriculture Sciences,

leading researcher laboratory and analytical center

Seredin T.M. - PhD in Agriculture,

Senior Researcher

Baranova E.V. - PhD in Agriculture,

Senior Researcher

Koshevaropv A.A. - researcher laboratory and analytical center

FSBSI Federal Scientific Vegetable Center

Selectsionnaya St. 14

VNIISSOK, Odintsovo region,

Moscow region, 143072, Russia

*E-mail: Pavlov.l.v@vniissok.ru

** E-mail: segolubkina45@gmail.com

The requirements for garlic powder enriched with selenium, dried by convective drying and homogenized, are established. Selenium-enriched vegetables have special healing properties and are of interest as a source of selenium. Garlic enriched with selenium is grown in a number of countries (including the USA, Sabinsa) and produced in the form of capsules, tablets and granules (BAA), as drugs that can protect against cardiovascular diseases and cancer. The technical conditions of dried garlic with a high content of selenium were studied and identified. Based on these indicators, a standard has been developed "Dried garlic with high content of selenium. Technical conditions». The standard was developed for the first time for the Russian Federation. Sodium selenate was applied to the soil with a total dose of $75 \mathrm{mg} / \mathrm{m}^{2}$ For drying, garlic bulbs in biological ripeness, standard and non-standard, without damage by diseases and pests were used. Cloves were peeled, ground, and dried in a drying cabinet at a temperature of $70^{\circ} \mathrm{C}$ to constant weight. The resulting material was homogenized, the powder was stored in tightly sealed plastic bags.

Keywords: standart, dried garlic with elevated level of selenium, technical conditiond.

For citation: Shilo L.M., Pavlov L.V., Golubkina N.A., Seredin T.M., Baranova E.V., Koshevaropv A.A. STANDARD OF ORGANIZATION FOR GARLIC POWDER ENRICHED BY SELENIUM. Vegetable crops of Russia. 2019;(1):60-64. (In Russ.) DOl:10.18619/2072-9146-2019-1-60-64

2013). Наиболее важными биологически активными соединениями чеснока, ответственными за антиканцерогенные свойства, являются соединения серы: ди- и трисульфиды, а также метилированные формы селенсодержащих аминокислот и пептидов: Se-Met-Se-Cys и ү-глутамил-Se-Met-Se-Cys (Dong et al., 2001; Fang et al., 2012; Ip, Ganther, 1992; Ip, Lisk, 1995; Yang et al., 2005). Последние обладают существенно более высокой противораковой активностью, чем соответствующие серосодержащие соединения (lp et al, 1992). Установлено, что селенообогащенный чеснок в 2 раза более эффективен в защите организма от аденокарциномы, чем селенообогащен- 
ные дрожжи, благодаря высоким концентрациям ү-глутамилSe-Met-Se-Cys (lp et al., 2000). Доказан широкий спектр биологического действия селенообогащенного чеснока, включающий защиту от токсического действия тяжелых металлов, таких как As, Cd, Hg, Pb и др. (Zhao et al., 2013), мощное антиоксидантное, кардиопротекторное, противовоспалительное и антибактериальное действие. Высокая биологическая активность характерна также и для продуктов переработки чеснока, обогащенного селеном: масла чеснока, спиртовых экстрактов и порошка (Bayan et al, 2014; Escudero et al, 2012).

Низкий уровень обеспеченности селеном населения большинства регионов России и широкое распространение кардиологических и онкологических заболеваний (Голубкина и др, 2017) определяет острую необходимость разработки и внедрения технологии получения чеснока, обогащенного селеном. Однако, выход на промышленный выпуск селен обогащенной продукции требует разработки и утверждения соответствующей документации.

Целью настоящей работы была разработка ОСТ на порошок чеснока, обогащенного селеном.

\section{Материалы и методы}

Изучены и определены технические условия чеснока сушеного с повышенным содержанием селена

Чеснок (сорт Добрыня) выращивали на опытном поле ФГБНУ ФНЦО. Селенат натрия вносили в почву в дозе 75 $\mathrm{M} \Gamma / \mathrm{M}^{2}$
Для сушки использовали луковицы чеснока биологической спелости, стандартные и нестандартные, без повреждения болезнями и вредителями.

Зубки очищали от шелухи, измельчали и высушивали в сушильном шкафу при температуре $70^{\circ} \mathrm{C}$ до постоянной массы. Полученный материал гомогенизировали, порошок хранили в герметично закрытых полиэтиленовых пакетах.

Содержание селена устанавливали флуорометрически (Alfthan, 1984). Уровень накопления полифенолов определяли с использованием реактива Фолина-Чиколтау (Golubkina et al., 2017), на спектрофотометре Unico 2804 UV (США). Концентрацию полифенолов рассчитывали, используя калибровочную кривую, построенную по 5 концентрациям галловой кислоты (0-90 мкг/мл), и выражали в мг-эКв галловой кислоты на 100 г сухой массы.

Уровень антиоксидантной активности определяли по методу (Максимова и др., 2001), основанному на титровании раствора перманганата калия экстрактом чеснока в кислой среде. Результаты выражали в мг-экв. галловой кислоты на 100 г сухой массы.

Уровень сахаров устанавливали цианидным методом (Кидин, 2008).

Содержание макро- и микроэлементов определяли в центре биотической медицина с использованием метода ИСП-МС на квадрупольном масс-спектрометре Nexion 300D; Perkin Elmer Inc., Shelton, CT 06484, USA.

Таблица 1. Показатели качества чеснока сушеного с повышенным содержанием селена

\section{Наименование показателей}

\section{Органолептические}

Внешний вид

$$
\begin{aligned}
& \text { Цвет } \\
& \text { Вкус }
\end{aligned}
$$

Запах

Консистенция

\begin{tabular}{|r|}
\hline порошкообразн \\
желто-белый \\
Острый чесночн \\
свойственный чес \\
Сыпучая \\
\hline не более 0,1\% \\
Не менее 1500 \\
$15,4-16,5$ \\
\hline $500-750$ \\
\hline $3500-4000$ \\
\hline
\end{tabular}

\section{физико-химические}

Массовая доля влаги, \%

Содержание селена, мкг/кг С.м.

Сумма сахаров, \%

Полифенолы, мг ГK/100 г

Общая AOA, мг ГK/100 г

\author{
порошкообразный \\ Острый чесночный \\ свойственный чесноку
}

Сыпучая

\section{Характеристика и нормы}

\section{Table 1. Quality indicators of garlic dried with a high content of selenium}

\section{Parameter}

Parameter

Appearence

Color

Taste

Flavor

Consistency

\section{Characteristics and limits}

\section{organoleptic}

powder

Yellow-white

Spicy garlic

Peculiar to garlic

loose

\section{Physic-chemical}

Moisture content, \%

Not more than $0,1 \%$

Selenium content, $\mu \mathrm{g} / \mathrm{kg}$ d.w.

Not less than 1500

Total sugar content, \%

15.4-16.5

Polyphenols, mg-eq GA/100 g

500-750

Total AOA, mg-eq GA/100 g

$3500-4000$ 
Статистическую обработку результатов осуществляли с использованием критерия Стьюдента на компьютерной программе Excel.

\section{Результаты и обсуждения}

На основе результатов обогащения чеснока селеном в полевых условиях (Голубкина и др., 2018) разработан стандарт организации «Чеснок сушеный с повышенным содержанием селена. Технические условия». Стандарт разработан впервые для РФ.

В первом разделе стандарта определена область применения. Настоящий стандарт распространяется на чеснок обогащенный селеном, высушенный методом конвекционной сушки и гомогенизированный.

Во втором разделе приведен перечень государственных нормативных документов, на которые даны ссылки.

В третьем разделе даны термины, определения и сокращения.

В четвертом разделе излагаются технические требования к качеству чеснока сушеного с повышенным содержанием селена, указанные в таблице 1,2,3, а также требования к упаковке и маркировке. По качественным показателям чеснок сушеный с повышенным содержанием селена должен соответствовать нормам, указанным в табл. 1.

Показательно, что по содержанию полифенолов и общей антиоксидантной активности порошок чеснока, обогащенного селеном, превосходит порошок чеснока, выращенного по обычной технологии без обогащения (рис.1,2) Данные рис. 1,2 показывают, что уровни антиоксидантной активности и содержание полифенолов определяются не только уровнем обогащения чеснока селеном, то также местом выращивания. Так, наибольшие показатели антиоксидантной активности оказались характерны для чеснока, привезенного из Тайланда, и порошка чеснока производства фирмы Индана. Низкие уровни антиоксидантной активности и содержания полифенолов были выявлены для порошка чеснока, производимого в Екатеринбурге и Польше.

Установлено, что около 20\% суточной потребности человека в селене может быть восполнено при потреблении 10 г порошка чеснока, обогащенного селеном.

По микробиологическим показателям чеснок сушеный с повышенным содержанием селена должен соответствовать требованиям, указанным в СанПиН 2.3.2.1078-01, п. 1.6.2. (табл.2). Содержание патогенных микроорганизмов не должно превышать допустимые уровни.

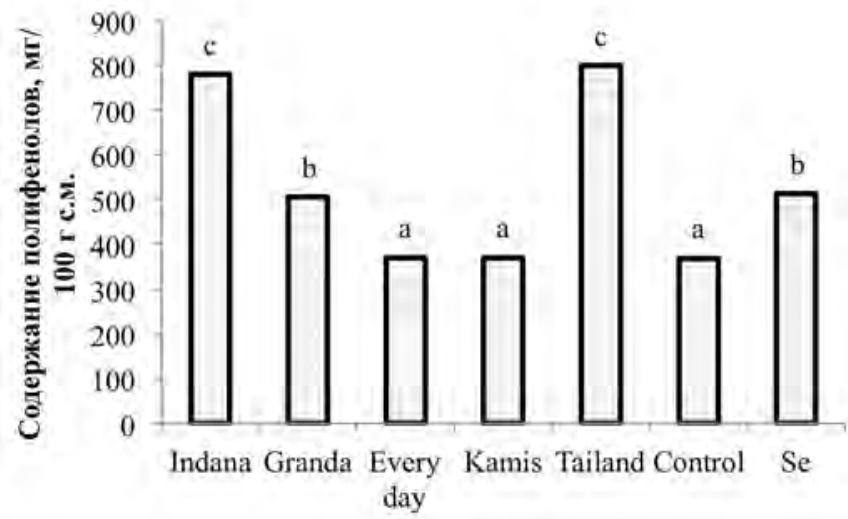

Рис.1. Содержание полифенолов в порошке чеснока, поступающего в розничную продажу, порошке чеснока, выращиваемого на опытных полях ФГБНУ ФНЦО и обогащенного селеном (значения с одинаковыми индексами статистически не различаются при Р>0.05).

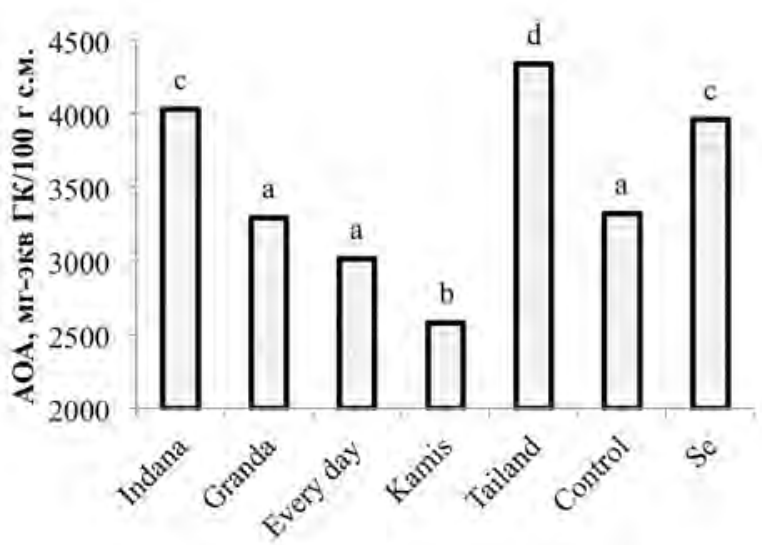

Рис.2. Общая антиоксидантная активность порошка чеснока порошке чеснока, поступающего в розничную продажу, выращиваемого на опытных полях ФГБНУ ФНЦО и обогащенного селеном (значения с одинаковыми индексами статистически не различаются при Р>0.05)

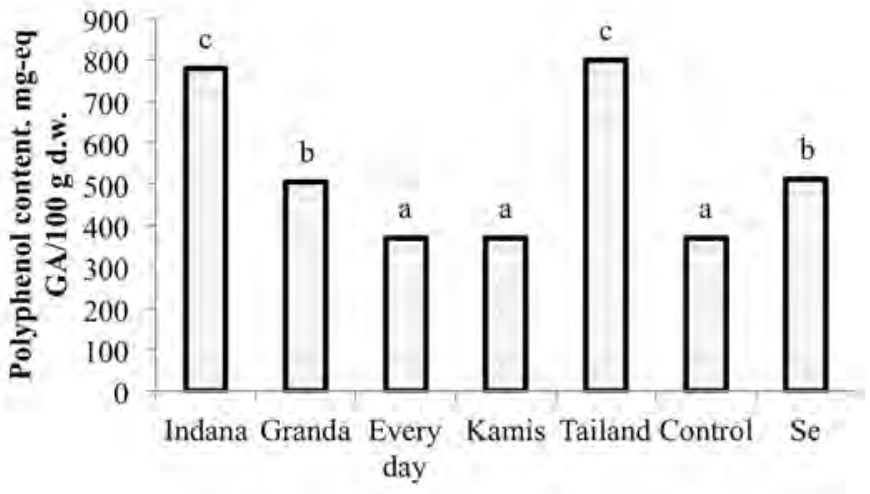

Fig.1. Polyphenol content in retail garlic powder, garlic cultivated at the experimental fields of Federal scientific center of vegetable production and fortified with selenium (values with similar indexes do not differ statistically at $P>0.05)$.

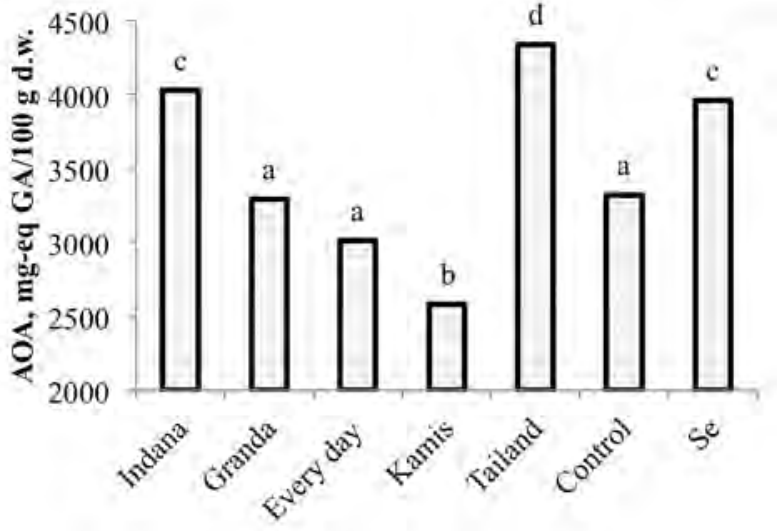

Fig.2 Total antioxidant activity of retail garlic powder, garlic cultivated at the experimental fields of Federal Scientific Vegetable Center and fortified with selenium (values with similar indexes do not differ statistically at $P>0.05$ ). 
Таблица 2. Микробиологические показатели чеснока сушеного с повышенным содержанием селена

\section{Наименование показателей}

Количество мезофильных аэробных и факультативно-анаэробных микроорганизмов, КОЕ/г, не более

БГКП - бактерии группы кишечных палочек (колиформы), в 0,01г

Патогенные микроорганизмы, в том числе Salmonella в 25 г

Плесени $\mathrm{KOE} / г$, не более

Bacillus cereus $\mathrm{KOE} / г$, не более

\section{Норма}

$5 \times 10^{5}$

не допускаются

не допускаются

$5 \times 10^{2}$

$1 \times 10^{3}$

Table 2. Microbiological indicators of dried garlic with a high content of selenium

\section{Parameter}

Количество мезофильных аэробных и факультативно-анаэробных микроорганизмов, COE/g, не более not more than

coliform bacteria, per $0,01 \mathrm{~g}$

Pathogenic microorganisms including Salmonella per $25 \mathrm{~g}$

Mildew $\mathrm{COE} / \mathrm{g}$, not more than

Bacillus cereus $\mathrm{KOE} /\ulcorner$, not more than

На переработку не допускают чеснок, в котором содержание нитратов, пестицидов, радионуклидов и токсичных элементов превышает допустимые уровни, установленные СанПиН 2.3.2.1078-01 (табл. 3).

\section{Maximum allowable level}

$5 \times 10^{5}$

Not allowed

Not allowed

$$
5 \times 10^{2}
$$$$
1 \times 10^{3}
$$

В пятом разделе указаны правила приемки соответственно ГОСТ 13341.

Шестой раздел - методы контроля. Отбор проб, определение внешнего вида, цвета, вкуса, запаха, массовой доли

Таблица 3. Показатели безопасности чеснока сушеного с повышенным содержанием селена

\section{Показатели}

Мышьяк, мг/кг, не более

Свинец, мг/кг, не более

Кадмий, мг/кг, не более

Ртуть, мг/кг, не более

Нитраты, мг/кг, не более

\section{Норма}

1,6

4,0

0,24

0,16

1600

Пестициды, мг/кг, не более:

ГХЦ (сумма изомеров)

ДДТ и его метаболиты радионуклиды, БК/кг, не более

Цезий 137

600

Стронций 90

Table 3. Safety performance of dried garlic with a high selenium content

\section{Parameters}

As, $\mathrm{mg} / \mathrm{kg}$, not more than

$\mathrm{Pb}, \mathrm{mg} / \mathrm{kg}$, not more than

$\mathrm{Cd}, \mathrm{mg} / \mathrm{kg}$, not more than

$\mathrm{Hg}, \mathrm{mg} / \mathrm{kg}$, not more than

Nitrates, mg/kg, not more than

Pestiocides, mg/kg, not more than:

HCC (sum of isomers)

DDT and its metabolites, radionuclides, BC/kg, not more than

Cs 137

Sr 90

\section{Maximum allowable level}

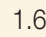

4.0

0.24

0.16

1600

0,8

200 
влаги - по ГОСТ 13340, ГОСТ 28561. Определение содержание селена - по МУК 4.033.11.95. Определение содержания ртути - по ГОСТ 26927, кадмия - по ГОСТ 26933, мышьяка по ГОСТ 26930, свинца - по ГОСТ 26932. Количество мезофильных аэробных и факультативно-анаэробных микроорганизмов определяют по ГОСТ 10444.15, бактерии группы кишечных палочек - по ГОСТ 31747, патогенные микроорганизмы - по ГОСТ 31659, плесени - по ГОСТ 10444.12, Bacillus cereus - по ГОСТ 10444.8.

Седьмой раздел стандарта - транспортирование и хранение, осуществляют в соответствии с ГОСТ 13342. Срок хранения порошка чеснока сушеного с повышенным содержанием селена в герметичной таре 24 месяца с даты изготовления и хранении при температуре не выше $+20^{\circ} \mathrm{C}$ и относительной влажности воздуха не более 75\%, в не герметичной таре - до 3 месяцев при условии соблюдения температурного режима от +18 до $20^{\circ} \mathrm{C}$ и относительной влажности воздуха не более $75 \%$.

В восьмом разделе приведены требования безопасности для здоровья людей, охраны окружающей среды и безопасности труда по ГОСТ 12.3.041. и ГОСТ 12.0.004.

Разработка стандарта организации на обогащенный селеном чеснок представляется, таким образом, особенно важной в связи с возможностью импортозамещения. Кроме того, исследования на добровольцах и выпуск соответствующей приправы функционального назначения возможны только при наличии ГОСТ, а сам порошок обогащенного чеснока в настоящее время ожидают медики, в частности, селенодефицитных регионов Хабаровского края, Иркутской области, Чеченской республики и Монголии.

\section{- Литература}

1. Голубкина Н.А., Синдирева А.В., Зайцев В.Ф. Внутрирегиональная вариабильность селенового статуса населения//Экология юга России. - 2017. - №1 - С.107127.

2. Голубкина Н.А., Середин Т.М., Кошеваров А.А., Шило Л.М., Баранова Е.В., Павлов Л.В. Порошок чеснока, обогащенного селеном// Микроэлементы в медицине. 2018. $-19(1)$. - C.43-50.

3. Кидин В.В., Дерюгин И.П., Кобяенко В.И. Практикум по агрохимии. Москва: изд. Колос, 2008: 236-240.

4. Максимова Т.В., Никулина И.Н., Пахомов Б.П., Шарина Е.И., Чакова З.В. Арзамасцев А.П. Метод определения антиоксидантной активности пат. РФ 2170930 C1, 2001

5. Alfthan G. A micromethod for the determination of selenium in tissues and biological fluids by single-test-tube fluorimetry//Anal. Chim. Acta. - 1984. - Vol. 65. - P.187-194.

6. Bayan L., Koulivand P.H., Gorji A. Garlic: a review of potential therapeutic effects//Avicenna J. of Phytomedicine. - 2014. - Vol.4 (1). - P.1-14.

7. Dong Y., Lisk D., Block E., Ip C. Characterization of the biological activity of Y-glutamylSe-methyl-Se-Cys: a novel, naturally occurring anticancer agent from garlic//Cancer Res. - 2001. - Vol. 61(7). - P.2923-2928.

8. Escudero L.B., Monasterio R.P., Lipinski V.M., Filippini M.F., Wuilloud R.G. Selenized garlic: a future prospect or already a current functional food?//Rev. FCS UNCUYO-2012 Vol.44(1). - P.301-318.

9. Fang Y., Luo P., Hu Y., Ma N., Yang W., Xin Z., Zhao L., Hu Q. Bioaccumulation and speciation analysis of selenium in garlic (Allium sativum L)//Food Sci. - 2012. - Vol.33. - P.1-5. 10. Golubkina N.A., Kosheleva O.V., Krivenkov L.V., Dobrutskaya H.G., Nadezhkin S. Caruso G. Intersexual differences in plant growth, yield, mineral composition and antioxidants of spinach (Spinacia oleracea L.) as affected by selenium form//Sci. Hort. - 2017. Vol.225. - P.350-358.

11. Ip, C., Birringer, M., Block, E., Kotrebai, M., Tyson, J.F., Uden, P.C., Lisk, D.J. Chemical speciation influences comparative activity of selenium-enriched garlic and yeast in mammary cancer prevention//J Agr Food Chem. - 2000. - Vol.48. - P.20622070.

12. Ip C., Ganther H.E. Comparison of selenium and sulfur analogs in cancer prevention// Carcinogenesis. - 1992. - Vol.1. - P.1167-1171.

13. Ip C., Lisk D.J. Efficacy of cancer prevention by high selenium garlic is primarily dependent on the action of selenium//Carcinogenesis. - 1995. - Vol.16. - P.2649-2652. 14. Mikaili P, Maadirad S, Moloudizargari M, Aghajanshakeri S, Sarahroodi S Therapeutic Uses and Pharmacological Properties of Garlic, Shallot, and Their Biologically Active Compounds//Iran J Basic Med Sci. - 2013. - Vol. 16(10). - P.1031 1048 .

15. Yang S., Wu T., Wu Y. Research progress on anti-cancer active substances in selenium rich garlic//J. Hubei Inst.Nationalities. - 2005. - Vol. 23. - P.134-136.

16. Zhao J., Gao Y., Li Y.-F., Hu Y., Peng X., Dong H., Li B., Chen C., Chai Z. Selenium inhibits the phytotoxicity of mercury in garlic (Allium sativum)//Environ.Res. - 2013. Vol.125. - P.75-81.
Производство порошка, обогащенного селеном, в качестве приправы функционального назначения не требует крупных промышленных площадей и доступно малому бизнесу, что делает реальным выпуск желаемой продукции.

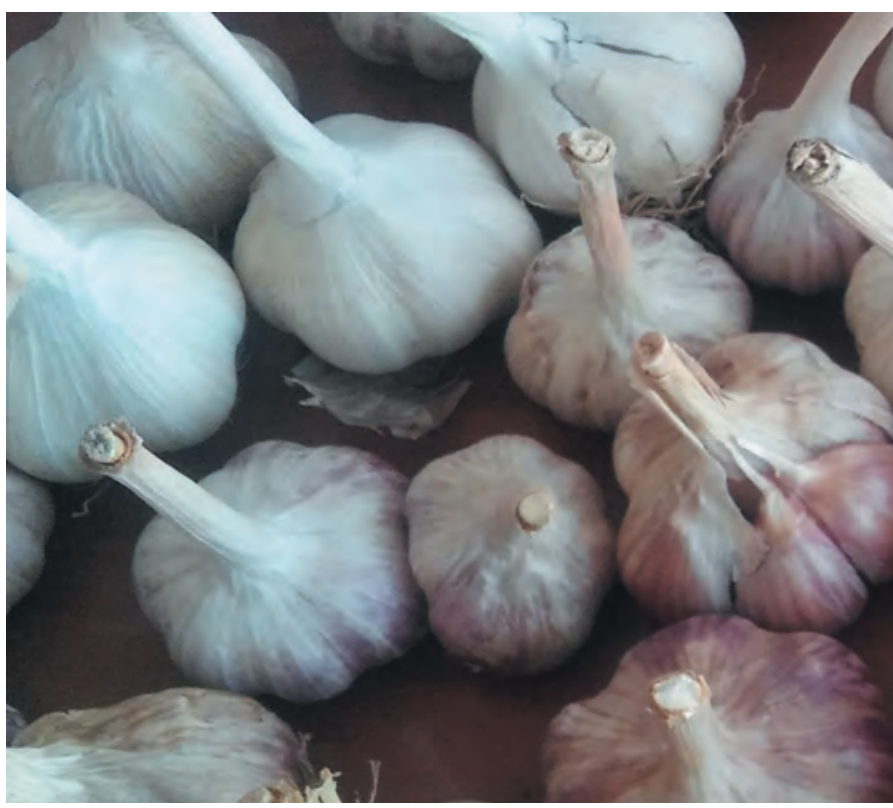

- References

1. Golubkina N.A., Sindireva A.V., Zaitsev V.F. Interregional variability of the human selenium status//Ecology of the South of Russia. - 2017. - №1. - C.107-127.

2. Golubkina N.A., Seredin T.M., Koshevarov A.A., Shilo L.M., Baranova H.V., Pavlov L.V. Powder of garlic enriched with selenium//Trace elements in medicine. - 2018. -19(1). - P.43-50.

3. Kidin V.V., Derugin I.P., Kobiaenko V.I. Agropchemical network. Moscow, Kolos, 2008: $236-240$.

4. Maximova T.V., Nikulina I.N., Pakhomov B.P., Sharina H.I., Chakova Z.V., Arzamastsev A.P. Method of antioxidant activity determination, RF pat. 2170930 C1, 2001.

5. Alfthan G. A micromethod for the determination of selenium in tissues and biologica fluids by single-test-tube fluorimetry//Anal. Chim. Acta. - 1984. - Vol. 65. - P.187-194. 6. Bayan L., Koulivand P.H., Gorji A. Garlic: a review of potential therapeutic effects//Avicenna J. of Phytomedicine. - 2014. - Vol.4 (1). - P.1-14.

7. Dong Y., Lisk D., Block E., Ip C. Characterization of the biological activity of Y-glutamyl-Se-methyl-Se-Cys: a novel, naturally occurring anticancer agent from garlic//Cancer Res. - 2001. - Vol. 61(7). - P.2923-2928.

8. Escudero L.B., Monasterio R.P., Lipinski V.M., Filippini M.F., Wuilloud R.G. Selenized garlic: a future prospect or already a current functional food?//Rev. FCS UNCUYO2012-Vol.44(1). - P.301-318

9. Fang Y., Luo P., Hu Y., Ma N., Yang W., Xin Z., Zhao L., Hu Q. Bioaccumulation and speciation analysis of selenium in garlic (Allium sativum L)//Food Sci. - 2012. - Vol.33. - P.1-5.

10. Golubkina N.A., Kosheleva O.V., Krivenkov L.V., Dobrutskaya H.G., Nadezhkin S., Caruso G. Intersexual differences in plant growth, yield, mineral composition and antioxidants of spinach (Spinacia oleracea L.) as affected by selenium form//Sci. Hort. 2017. - Vol.225. - P.350-358.

11. Ip, C., Birringer, M., Block, E., Kotrebai, M., Tyson, J.F., Uden, P.C., Lisk, D.J. Chemical speciation influences comparative activity of selenium-enriched garlic and yeast in mammary cancer prevention//J Agr Food Chem. - 2000. - Vol.48. - P.2062 2070.

12. Ip C., Ganther H.E. Comparison of selenium and sulfur analogs in cancer prevention// Carcinogenesis. - 1992. - Vol.1. - P.1167-1171.

13. Ip C., Lisk D.J. Efficacy of cancer prevention by high selenium garlic is primarily dependent on the action of selenium//Carcinogenesis. - 1995. - Vol.16. - P.26492652.

14. Mikaili P, Maadirad S, Moloudizargari M, Aghajanshakeri S, Sarahroodi S Therapeutic Uses and Pharmacological Properties of Garlic, Shallot, and Their Biologically Active Compounds//Iran J Basic Med Sci. - 2013. - Vol. 16(10). - P.10311048.

15. Yang S., Wu T., Wu Y. Research progress on anti-cancer active substances in selenium rich garlic//J. Hubei Inst.Nationalities. - 2005. - Vol. 23. - P.134-136.

16. Zhao J., Gao Y., Li Y.-F., Hu Y., Peng X., Dong H., Li B., Chen C., Chai Z. Selenium inhibits the phytotoxicity of mercury in garlic (Allium sativum)//Environ.Res. - 2013. Vol.125. - P.75-81. 